\title{
Radiofrequency catheter ablation in infants and children
}

\begin{tabular}{|c|c|}
\hline Adèle Greyling(*,\#), Joris Ector ${ }^{(*)}$ and Christophe Garweg ${ }^{(*)}$ & ABSTRACT \\
\hline $\begin{array}{l}\text { INTRODUCTION } \\
\text { The diagnosis and treatment of arrhythmias in children remain } \\
\text { challenging. Diagnosis is difficult due to the fact that infants } \\
\text { and young children cannot communicate symptoms and } \\
\text { often present with haemodynamic compromise. Antiarrhythmic } \\
\text { drugs, namely beta blockers, class Ic and class III drugs, were the } \\
\text { only treatment available for many years. Alternatives to medical } \\
\text { treatment include no treatment, surgical ablation and radio- } \\
\text { frequency catheter ablation. (I) Surgical ablation (including the } \\
\text { Maze procedure), a precursor to RF ablation, is much more } \\
\text { invasive and more commonly performed in complex arrhyth- }\end{array}$ & 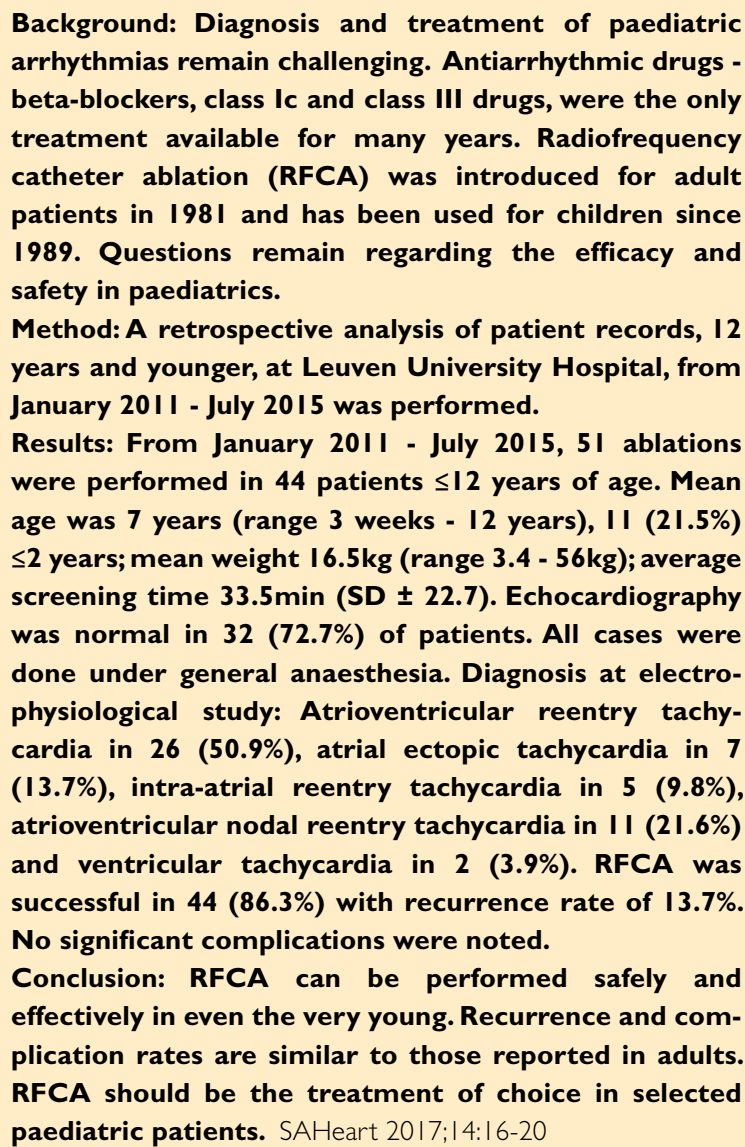 \\
\hline
\end{tabular}
mias in older patients with concurrent surgical intervention. RF ablation was first introduced in paediatric patients in 1989. However, various questions remain regarding the safety and efficacy.

\section{METHODS}

A retrospective analysis of patient records, 12 years and younger, at Leuven University Hospital, from January 201I July 2015 was performed. Patients' demographics including age, sex and weight; echocardiographic findings, indication for RFCA, screening time, outcomes and complications were recorded.

\section{RESULTS}

From January 201I - July 2015 a total of 51 ablations were performed in 44 patients. All cases were performed under general anaesthesia. The mean age was 7 years (with a range from 3 weeks - 12 years); II patients (21.5\%) were younger than the age of 2 years. Weights ranged from $3.4-56 \mathrm{~kg}$

\begin{abstract}
Background: Diagnosis and treatment of paediatric treatment available for many years. Radiofrequency catheter ablation (RFCA) was introduced for adult 1989. Questions remain regarding the efficacy and safety in paediatrics. years and younger, at Leuven University Hospital, from January 20 I I - July 2015 was performed.

were performed in 44 patients $\leq 12$ years of age. Mean age was 7 years (range 3 weeks - 12 years), 11 (2I.5\%) creening time $33.5 \mathrm{~min}$ (SD \pm 22.7 ). Echocardiography was normal in $32(72.7 \%)$ of patients. All cases were hysiolo cardia in 26 (50.9\%), atrial ectopic tachycardia in 7 (13.7\%), intra-atrial reentry tachycardia in $5(9.8 \%)$ trioventricular nodal reentry tachycardia in II (21.6\%) successful in 44 (86.3\%) with recurrence rate of $13.7 \%$. No significant complications were noted. effectively in even the very young. Recurrence and complication rates are similar to those reported in adults. paediatric patients. SAHeart 2017;14:16-20
\end{abstract}

(mean of $16.5 \mathrm{~kg}$ ). The average screening time was $33 \mathrm{~min}$ $(\mathrm{SD} \pm 22.7)$.

Echocardiography was normal in 32 (72.7\%) of cases. Abnormalities on echocardiography were: Epstein's with perimembranous VSD, a secundum ASD, hypertrophic cardiomyopathy, tricuspid atresia with right ventricular outflow tract conduit and percutaneous Melody valve, tetralogy of Fallot, double outlet right ventricle (DORV), hypoplastic left heart $(\mathrm{HLH})$ syndrome and premature closure of the ductus arteriosus.

Diagnosis at invasive electrophysiology study was atrioventricular reentry tachycardia (AVRT) in 26 (50.9\%), ectopic atrial tachycardia (EAT) in 7 (13.7\%), intraatrial re-entry tachycardia (IART) in 5 (9.8\%), atrioventricular nodal reentry tachycardia in 11 (21.6\%) and ventricular tachycardia (VT) in 2 (3.9\%) patients. The 2 cases of $\mathrm{VT}$ were left ventricular outflow tract 
tachycardia (LVOT VT) in a patient with a normal heart, and right ventricular outflow tract tachycardia (RVOTVT) originating from under the Melody valve in the patient with post operative tricuspid atresia.

The acute success rate was $86.3 \%$ (44 ablations), with a recurrence rate of $13.7 \%$. Recurrence occurred in a 5-year-old with Epstein's anomaly and Wolf Parkinson White syndrome (WPW), a 6-year-old with 2 accessory pathways (posteroseptal and a concealed right lateral accessory pathway [AP]), a 3-yearold with a right anterolateral and left lateral AP, a 2-month-old with HLH syndrome and IART, a 4-month-old with right atrial isomerism, DORV and EAT, and a 10-month-old with a structurally normal heart and EAT. In one case, a 3-year-old with a concealed anteroseptal AP, ablation was abandoned due to the high risk of AV block. No significant complications were found.

\section{DISCUSSION}

In recent years RFCA has increasingly been used as curative treatment for a variety of arrhythmias in children and adolescents. In patients, over 12 - $15 \mathrm{~kg}$ in experienced paediatric electrophysiology centres the success rate is high and the risk of severe complications is low, comparable to data from adult studies. ${ }^{(2-4)}$ It remains an invasive procedure though, and before deciding whether to proceed to RF ablation a thorough understanding is needed of the tachycardia substrates, the natural history and outcomes of RF ablation.

\section{Tachycardia substrates in children}

Supraventricular tachycardia (SVT) are by far the most prevalent arrhythmias in children without structural congenital heart disease (CHD). In all ages, AVRT due to an AP is the most common with a prevalence of 0.1 - $0.15 \%$. In infants, AVRT accounts for $80 \%$ of cases, EAT for $15 \%$ and AVNRT for $5 \%$. Permanent junctional reciprocating tachycardia (PJRT) and congenital junctional ectopic tachycardia (JET) are less commonly encountered but, both may be incessant and lead to ventricular dysfunction. JET is also uncommonly encountered in neonates with CHD undergoing surgery. Atrial flutter is rarely seen outside the neonatal period. With increasing age, AVNRT becomes more common, approaching adult incidence. In the age group I - 5 years AVRT remains most common at $65 \%$, AVNRT in $25 \%$ and EAT in $10 \%$ of cases. ${ }^{(5)}$ Atrial fibrillation (AF) is extremely rare, occurs most typically in patients with manifest pre-excitation and initiation might be due to degeneration from AVRT. ${ }^{(6)}$

Sustained $\mathrm{VT}$ is rare in children with an estimated incidence of between 0.2 and 0.8 per 10000 children. ${ }^{(7)}$

In patients with CHD the arrhythmia may be associated with the underlying abnormality or with surgical intervention which provides a highly favourable substrate for re-entrant arrhythmias. $^{(8)}$

\section{Clinical presentation and natural history}

There are very few natural history studies concerning tachycardia in childhood, most looking at AVRT. It is estimated that most patients with AVRT in infancy will have no recurrences once medication is stopped after the age of I year with tachycardia recurring in approximately $30 \%$ at an average age of 7 - 8 years. ${ }^{(9)}$ The conduction properties of both the AP and $\mathrm{AV}$ node change as the child matures with loss of anterograde conduction over the AP in as many as $40 \%$ of patients, making SVT non-inducible. However, if tachycardia and WPW coexist beyond 5 years of age it is likely to to still be present after a decade in 75\% of patients. On occasion, with prolonged periods of tachycardia, haemodynamic collapse might result. In most cases, though, recurrences are well tolerated. It has been reported that up to 10\% of patients with WPW and AVRT may present with life threatening symptoms. ${ }^{(9)}$ Prolonged tachy-cardia may lead to tachycardiainduced cardiomyopathy and needs to be distinguished from other causes of cardiomyopathy as it is curable. Sudden cardiac death (SCD) may occur due to rapid conduction over the AP during atrial fibrillation resulting in ventricular fibrillation (VF). The risk for SCD is estimated to be up to $1.3-1.6 \%$ with the highest incidence in the first 2 decades of life. ${ }^{(10)}$ Risk stratification for a life threatening-arrhythmia on history alone is problematic with red flags being younger age ( $<30$ years), male gender, history of AF, prior syncope, associated CHD and familial WPW. Noninvasive risk stratification includes measuring the Shortest Pre-Excited R-R Interval (SPERRI) on ECG during AF, with an SPERRI of 220 - 250ms being a risk for SCD, and proving the disappearance of preexcitation at physiological heart rates (e.g. Holter or exercise stress test). Interobserver reliability of loss of delta wave remains problematic as preexcitation may be masked by rapid AV conduction.

With VT the outcome is favourable, especially in infants presenting with RVOT $V T$. In a large retrospective, multicentre analysis of idiopathic childhood VT, only nine of 98 patients required RFCA. ${ }^{(6)}$ About half of patients with sustained $\mathrm{VT}$ have no structural heart disease and are divided between neonatal idiopathic left and idiopathic right VTs, with the majority (53\%) originating from the right ventricle. Sustained $V T$ disappears in half of the cases with no underlying CHD, with the only mortality having been reported in patients with underlying $\mathrm{CHD}$. Thus, sustained VT in children with no underlying CHD is rare and carries a good prognosis. ${ }^{(7)}$

\section{Diagnostic electrophysiology study (EPS)}

In most cases, the mechanism and hence treatment of arrhythmias, can be largely established by history taking, (12) lead electrocardiogram (ECG) and using non-invasive techniques like a bipolar oesophageal electrode to perform an EPS. Atrial overdrive pacing can also be performed via an oesophageal electrode and is successful in virtually all cases of SVT and up to $73 \%$ of cases of IART/ atrial flutter.(11) The indications for EPS and ablation are almost similar in children with SVT with the exception of risk stratification for SCD in children with 
asymptomatic preexcitation. Due to the limitations of noninvasive risk stratification up to $84 \%$ of surveyed paediatric electrophysiologists use some form of EPS in asymptomatic children with WPW and 77\% would perform RFCA when the SPERRI is $<240 \mathrm{~ms}$. When the anterograde characteristics of the AP is not clear on noninvasive testing invasive EPS should be considered. Risk factors for $V F$ and SCD are SPERRI $\leq 220 \mathrm{~ms}$, APERP (effective refractory period) of $<240 \mathrm{~ms}$, multiple APs and possibly septal bypass tracks. ${ }^{(9)}$

EPS is usually performed in conjunction with RFCA once it has been decided to eliminate a documented $\mathrm{VT}$. (7)

\section{Radiofrequency catheter ablation}

The indications for RFCA were reported by 2 PACES/HRS expert consensus documents and are documented in Table $\left.\right|^{(8)}$ and in Table $\|$ the indications for RFCA in children with idiopathic ventricular arrhythmias. (7) In addition to these recommendations, RFCA may also be considered in patients with asymptomatic preexcitation and $\mathrm{CHD}$ before surgery that might limit access for future catheter based procedures. ${ }^{(10)}$ The success and complication rates reported by the Paediatric Radiofrequency Catheter Ablation Registry and the Paediatric Electrophysiology Society (PACES) are similar to those in adults. The acute overall success rate is very high at around 95\% for AVRT or AVNRT, with higher success rates for left sided AP and particularly left free-wall pathways (97.8\%) than right free-wall pathways $(90.8 \%)$. $(2,4,12)$

Complications reported included AV block, bleeding, stroke, infection, damage to the cardiac valves, coronary artery spasm and radiation exposure. With diagnostic EPS the most common complication was haematoma and with RFCA, AV nodal block (1.2\%) limited to ablation of septal pathways (3.0\%) and AVNRT (2.1\%). Techniques to avoid AV block include intubation and apnoea during ablation, pacing in the coronary sinus to monitor AV conduction, using lower temperatures and power settings, ablating during tachycardia and mapping the position of the His-bundle prior to application. (13)

The number of APs present may also influence the safety and efficacy of RFCA. ${ }^{(14)}$ Those with multiple pathways, compared to patients with single AP, had a higher incidence of antidromic tachycardia, a shorter anterograde AP effective refractory period, longer fluoroscopy time and a larger number of unsuccessful attempts. Success rate (92\% vs. 93\%) and recurrence rate (1.7\% vs. 2.1\%) were, however, similar. Other complications, including coronary artery injury during endocardial ablation near the AV groove, occur much less frequently.(15)

In a large retrospective, multicentre analysis of idiopathic childhood VT only 9 of 98 patients required RFCA, with a success rate of $78 \%$. $^{(13)}$

In infants less $<15 \mathrm{~kg}$ RFCA is generally deferred unless a specific indication exist, like refractory or life threatening arrhythmias
TABLE I: Indications for radiofrequency catheter ablation in paediatric patients.

\begin{tabular}{|c|c|}
\hline \multicolumn{2}{|c|}{ Class } \\
\hline \multirow[t]{6}{*}{1} & $\begin{array}{l}\text { WPW syndrome following an episode of aborted sudden } \\
\text { cardiac death. }\end{array}$ \\
\hline & $\begin{array}{l}\text { The presence ofWPW syndrome associated with syncope } \\
\text { when there is a short R-R interval during atrial fibrillation } \\
\text { (preexcited R-R interval } 250 \mathrm{~ms} \text { ) or the anterograde effective } \\
\text { refractory period of the AP measured during programmed } \\
\text { electrical stimulation is }<250 \mathrm{~ms} \text {. }\end{array}$ \\
\hline & $\begin{array}{l}\text { Chronic or recurrent SVT associated with ventricular } \\
\text { dysfunction. }\end{array}$ \\
\hline & $\begin{array}{l}\text { Recurrent } \mathrm{VT} \text { that is associated with haemodynamic } \\
\text { compromise and is amenable to catheter ablation. }\end{array}$ \\
\hline & $\begin{array}{l}\text { WPW syndrome and recurrent and/or symptomatic SVT and } \\
\text { age }>5 \text { years. }\end{array}$ \\
\hline & $\begin{array}{l}\text { WPW syndrome and palpitations with inducible sustained SVT } \\
\text { during EPS, age }>5 \text { years. }\end{array}$ \\
\hline \multirow[t]{2}{*}{$\| \mathrm{A}$} & $\begin{array}{l}\text { SVT, age }>5 \text { years, chronic AA therapy has been effective in } \\
\text { control of the arrhythmia. }\end{array}$ \\
\hline & $\begin{array}{l}\text { SVT, age }<5 \text { years (including infants), when AA medication, } \\
\text { including classes I and III are not effective or associated with } \\
\text { intolerable side effects. }\end{array}$ \\
\hline \multirow[t]{3}{*}{ IIB } & $\begin{array}{l}\text { WPW syndrome and recurrent and/or symptomatic SVT and } \\
\text { age }<5 \text { years. }\end{array}$ \\
\hline & Single or infrequent SVT (no pre-excitation), age $>5$ years. \\
\hline & $\begin{array}{l}\text { Asymptomatic preexcitation, age }>5 \text { years, no recognised } \\
\text { tachycardia, risks and benefits of procedure and arrhythmia } \\
\text { clearly explained. }\end{array}$ \\
\hline \multirow[t]{2}{*}{ III } & Asymptomatic preexcitation, age $<5$ years. \\
\hline & SVT controlled with conventional AA medication, age $<5$ years. \\
\hline
\end{tabular}

Class I: There is consistent agreement and/or supportive data that catheter ablation is likely to be medically beneficial or helpful for the patient.

Class II: There is a divergence of opinion regarding the benefit or medical necessity of catheter ablation. II A: The majority of opinions/data are in favour of the procedure. II B: There is clear divergence of opinion regarding the need for the procedure.

Class III: There is agreement that catheter ablation is not medically indicated and/or the risk of the procedure may be greater than benefit for the patient.

$A P=$ accessory pathway, $A V N=$ atrioventricular node, $E C G=$ electrocardiogram, $I A R T=$ intra-atrial reentrant tachycardia, SVT = supraventricular tachycardia, $V T=$ ventricular tachycardia, WPW $=$ Wolff-Parkinson-White,

$A A=$ antiarrhytmic therapy.

Adapted from Brugada J, et al. Pharmacological and non-pharmacological therapy for arrhythmias in the paediatric population: EHRA and AEPC-Arrhythmia working group joint consensus statement. Europace 2013;15:1337-1382 and Page RL, et al. 2015 ACC/AHA/HRS SVT Guideline. Circulation 2015; 132:e000-e000.

with associated ventricular dysfunction. Procedure modifications also need to be made for example using $4 \mathrm{~F}$ diagnostic catheter and $5 \mathrm{~F}$ ablation catheter, or a single catheter technique. In a retrospective analysis comparing RFCA in infants $<18$ months to older children no difference was found, either for success rate, or incidence of major complications. ${ }^{(16)}$ Secondary analysis of patients weighing $<15 \mathrm{~kg}$, including those older than 18 months, showed an increase in major, but not overall, complication rate. 


\begin{tabular}{|l|l|}
$\begin{array}{l}\text { TAABLE II: Indications for radiofrequency catheter ablation in } \\
\text { paediatric patients with idiopathic ventricular arrhythmias. }\end{array}$ \\
\hline I & $\begin{array}{l}\text { Ventricular dysfunction or haemodynamic compromise } \\
\text { presumed to be due to ventricular ectopy orVT; either as } \\
\text { primary therapy or with failed medical therapy. }\end{array}$ \\
\hline Intrafasicular verapamil-sensitive reentrant VT; either as primary \\
therapy or if not controlled by calcium-channel blockers.
\end{tabular}

Class I: There is consistent agreement and/or supportive data that catheter ablation is likely to be medically beneficial or helpful for the patient.

Class II: There is a divergence of opinion regarding the benefit or medical necessity of catheter ablation. II A: The majority of opinions/data are in favour of the procedure. II B: There is clear divergence of opinion regarding the need for the procedure. Class III: There is agreement that catheter ablation is not medically indicated and/or the risk of the procedure may be greater than benefit for the patient.

$V T=$ ventricular tachycardia.

Adapted from: Crosson, et al. PACES/HRS Expert consensus statement on the evaluation and management of ventricular arrhytmias in the child with a structurally normal heart. Heart Rhythm 20 1 4; 1 1:e55-e78.

\section{Mapping and ablation systems}

Conventional mapping using multipolar catheters placed at specific locations under fluoroscopy recording activation sequence at baseline and in response to various pacing protocols remain the gold standard for most children with structurally normal hearts. However, patients with congenital heart disease are often encountered in paediatric electrophysiology. Conventional mapping may be difficult due to inconsistent anatomical and surgical landmarks coupled with areas of low-voltage myocardium and scarring, leading to long procedure and fluoroscopy times. Three dimensional elctroanatomical mapping significantly facilitates these procedures.

The EnSite NavX system (St Jude Medical, St Paul, Minnesota, USA) uses standard electrophysiological catheters to sense the electrical signals transmitted between 3 pairs of electrode patches. Three dimensional reconstruction can thus be created and areas of interest annotated.

By serial acquisition of endocardial points, a 3 dimensional reconstruction can be created using elepctroanatomical mapping (CARTO, Biosense Webster, Diamond Bar, California, USA). The catheter tip can be located, in 3 dimensions, within the heart to within I mm using special catheters and a location magnet. Using a stable reference catheter, serial cardiac activation is acquired, colour coded and superimposed on the anatomical map. Surgical and anatomical structures can be added as may electrophysiologically important points like double potentials or areas of scar. Pre-procedure MRI/CT may be useful in patients with CHD as the images can be superimposed onto the anatomical map (CARTO-UNIVU) leading to better definition of anatomy and reducing radiation dose. The long-term outcome of ablation in patients with congenital heart disease has been shown to be improved by the use of electroanatomical mapping. ${ }^{(17)}$ Limiting factors in paediatric patients are the size of the patches and catheters and, in patients with non-sustained or haemodynamically unstable arrhythmias, the time needed to acquire the map.

\section{Cryoablation}

Cryoenergy has been shown to be a safe and effective alternative to RFCA for the ablation of tachycardia substrates in adult patients. ${ }^{(18-20)}$ Although modifications to the transcatheter delivery systems have made the use of cryoablation possible in paediatric patients, catheter size remains a problem in the smallest of patients.(21) Possible advantages of cryoablation compared to RFCA in particular include safety in ablation near the AV node by using cryomapping. Cryomapping allows for the evaluation of the acute, reversible effects of cryo before applying a permanent lesion. Another advantage is cryoadherence as the formation of an ice ball at the tip of the catheter permits adhesion of the catheter to the endocardium, thus increasing stability and reducing the need for fluoroscopy during ablation. There is also a decreased risk of thromboembolism and coronary artery stenosis after cryoablation compared to RFCA. ${ }^{(22)}$ Patient discomfort is also less during cryoapplication. ${ }^{(23)}$

The acute success rate for cryoablation for AVNRT is comparable with RFCA (94\% vs. 96\%), but the recurrence rate is higher (12\% vs. 6\%). ${ }^{(24)}$ The total success rate for APs is lower than RFCA (75\% vs. $92 \%$ ) but it is comparable for midseptal and anteroseptal APs (i.e. close to the His bundle). Thus cryoablation should probably be used specifically to ablate substrates close to the AV junction.

\section{CONCLUSION}

Radiofrequency catheter ablation provides a safe and effective treatment option for selected paediatric patients, including infants, with outcomes in experienced paediatric centres similar to those seen in the adult population. It may be considered as first line therapy in selected situations, including in infants with refractory and/or life threatening arrhythmias. An electrophysiololgy study should be considered in the patient with asymptomatic preexcitation, aged 5 years and older, due to the risk of sudden cardiac death.

\section{Conflict of interest: none declared.}




\section{REFERENCES}

I. Blaufox AD. Catheter ablation of tachyarrhythmias in small children. Indian Pacing and Electrophysiology Journal 2005;5(1):5 I-62.

2. Kugler JD, Danford DA, Houston KA, et al. Paediatric radiofrequency catheter ablation registry success, fluoroscopy time, and complication rate for supraventricular tachycardia: comparison of early and recent eras. J Cardiovasc Electrophysiol 2002; 1 3:336-41.

3. Hebe J, Hansen P, Ouyang F, et al. Radiofrequency catheter ablation of tachycardia in patients with congenital heart disease. Pediatr Cardiol 2000;21:557-75.

4. Van Hare GF, Javitz H, Carmelli D, et al. Prospective assessment after paediatric cardiac ablation: Demographics, medical profiles, and initial outcomes. J Cardiovasc Electrophysiol 2004;15:759-70.

5. Perry JC, Garson A Jr. Supraventricular tachycardia due to Wolff-ParkinsonWhite syndrome in children: Early disappearance and late recurrence. J Am Coll Cardiol 1999;16:1221-3.

6. Pfammater J-P, Paul T. Idiopathic ventricular tachycardia in infancy and childhood. A multicenter study on clinical profile and outcome. J Am Coll Cardiol 1999;33:2067-72.

7. Crosson et al. PACES/HRS expert consensus statement on the evaluation and management of ventricular arrhytmias in the child with a structurally normal heart. Heart Rhythm 20 14; I : e55-e78.

8. Brugada J, et al. Pharmacological and non-pharmacological therapy for arrhythmias in the paediatric population: EHRA and AEPC-Arrhythmia working group joint consensus statement. Europace 2013; I 5: 1337-1382.

9. Mitchell I Cohen, et al. PACES/HRS expert consensus statement on the management of the asymptomatic young patient with a Wolff-ParkinsonWhite (WPW, Ventricular Preexcitation) electrographic pattern. Heart Rhythm 20 12;9:1006-1024.

10. Page RL, et al. 2015 ACC/AHA/HRS SVT Guideline. Circulation 2015; 132:e000-e000

II. Saul JP. Transesophageal atrial recording and pacing. In: Walsh EP, Saul JP, Triedman JK, eds. Cardiac arrhythmias in children and young adults with congenital heart disease. Lippincott: Williams and Wilkins, 2001.

12. Van Hare GF, Carmelli D, Smith WM, et al. Prospective assessment after paediatric cardiac ablation: Design and implementation of the multicenter study. Pacing Clin Electrophysiol 2002;25:332-4I.

13. Pecht B, Maginot KR, Boramanand NK, et al. Techniques to avoid atrioventricular block during radiofrequency catheter ablation of septal tachycardia substrates in young patients. J Interv Card Electrophysiol 2002;7:83-8

14. Weng KP, Wolff GS, Young ML. Multiple accessory pathways in paediatric patients with Wolff-Parkinson-White syndrome. Am J Cardiol 2003;91: I 178-83.

15. Bertram H, Bokenkamp R, Peuster M, et al. Coronary artery stenosis after radiofrequency catheter ablation of accessory atrioventricular pathways in children with Ebstein's malformation. Circulation 200 I; 103:538-43.

16. Blaufox AD, Felix GL, Saul JP, et al. Radiofrequency catheter ablation in infants, 18 months old. When is it done and how do they fare? Circulation 2001;104:2803-8.26.

17. Triedman JK, Alexander ME, Love BA, et al. Influence of patient factors and ablative technologies on outcomes of radiofrequency ablation of intra-atrial reentrant tachycardia in patients with congenital heart disease. J Am Coll Cardiol 2002;39: 1827-35.
18. Rodriguez LM, Geller JC, Tse HF, et al. Acute results of transvenous cryoablation of supraventricular tachycardia (atrial fibrillation, atrial flutter, Wolff-Parkinson-White syndrome, atrioventricular nodal reentry tachycardia). J Cardiovasc Electrophysiol 2002; 1 3:1082-9.

19. Riccardi R, Gaita F, Caponi D, et al. Percutaneous catheter cryothermal ablation of atrioventricular nodal reentrant tachycardia: Efficacy and safety of a new ablation technique. Ital Heart J 2003;4:35-43.Lanzotti ME, De Ponti R, Spadacini G, Salerno-Uriarte JA.

20. Gaita F, Riccardi R, Hocini M, et al. Safety and efficacy of cryoablation of accessory pathways adjacent to the normal conduction system. J Cardiovasc Electrophysiol 2003; 14:825-9.

21. Dubuc M, Skanes AC, Roy D, et al. Catheter cryomapping and cryoablation of supraventricular tachycardia in man: Preliminary results. Pacing Clin Electrophysiol 2000;23:613.

22. Khairy $P$, Chauvet $P$, Lehmann J, et al. Lower incidence of thrombus formation with cryoenergy versus radiofrequency catheter ablation. Circulation 2003; 107:2045-50.

23. Lowe MD, Mearam M, Mason J, et al. Catheter cryoablation of supraventricular arrhythmias: A painlessalternative to radiofrequency energy. Pacing Clin Electrophysiol 2003;26:500-3.

24. Papez AL, Al-Ahdab M, Dick M 2nd, et al. Transcatheter cryotherapy for the treatment of supraventricular tachyarrhytmias in children: A single center experience. J Interv Card Electrophysiol 2006; 15:191-6. 